\title{
Development of a Physical Rehabilitation Therapy Model for Functional Ankle Instability with Strengthening Exercise and Proprioceptive Exercise Methods
}

\author{
Donal Syafrianto $^{1^{*}}$ and Arif Fadli Muchlis ${ }^{2}$
}

\author{
${ }^{1,2}$ Department of Health and Recreation, Faculty of Sport Sciences, Padang State University \\ *Corresponding author. Email: donalsyafrian@fik.unp.ac.id
}

\begin{abstract}
Functional ankle instability is a subjective feeling experienced by a person in the ankle that feels unsteady after a history of repeated injuries to the ankle which results in proprioceptive and neuromuscular deficits as well as decreased sports performance to end one's career in certain sports due to the emergence of disabilities. The purpose of this study was to develop a model of physical rehabilitation therapy in improving ankle functional stability in functional ankle instability using Strengthening exercise and Proprioceptive Exercise methods. The research method in this research is research and developmentt, namely by developing a training method in the case of functional ankle instability and a product test method that resulted in the research sample using an experimental method with a pre-test and post-test design. The therapeutic model produced in this study was tested on 20 male research samples, the study was conducted 3 times a week for 6 weeks with the research instrument using the Cumberland Ankle Instability Tool. The results showed that the provision of Strengthening Exercise and Proprioceptive Exercise on functional ankle instability had a significant effect on improving the value of ankle functional stability with a pre-test mean of $20.70 \pm 1.418$ and a post-test mean of $25.65 \pm 1.137$ with a value of $p$ $=0.000(\mathrm{p}<0.05)$. In conclusion, the combination of Strengthening Exercise and Proprioceptive Exercise can improve ankle functional stability in cases of functional ankle Instability.
\end{abstract}

Keywords: Functional Ankle Instability, Strengthening Exercise and Proprioceptive Exercise

\section{INTRODUCTION}

Ankle Sprain Chronic causes the ankle to become unstable or unstable, pain that can severely interfere with comfort and balance. About $85 \%$ of ankle injuries involve the lateral ligaments. ${ }^{1}$ This injury can damage the structures on the lateral ankle including muscles, nerves, ligaments, and tendons. Most of the patients who suffered an ankle injury lateral can be cured, but it is estimated 30-40\% develop Chronic Ankle instability. ${ }^{2}$ Ankle Sprain is the most common injury in adults and 
adolescents, namely 206 cases out of 100,000 people per year. ${ }^{3}$

Chronic ankle instability is a condition where there is repeated injury as a result of lateral ankle instability accompanied by sequelae such as pain, edema, "giving way", and limited range of motion, which occurs after repeated injury to the lateral ankle ligaments ${ }^{4}$

Via afferent nerve fibers, this information is integrated between the visual and ivestibular sensory systems with a complex control system that acts to control posture and coordination. The information entered into afferent nerves will change after the injury, this change will also occur in the correction of muscle contraction. Thus, damage to the mechanoreceptors around the ankle joint with the lateral ankle sprain can contribute to functional impairment and chronic instability after the initial injury. ${ }^{5}$

The initial injury can result in two types of dysfunction, namely Functional Ankle Instability and Mechanical Ankle Instability, which can affect recovery from acute injury and is an extension of Chronic Ankle Instability. Mechanical Ankle Instability includes pathological weakness, Arthrokinematics and

degenerative disorders. Functional

Ankle instability include disorders Propioception, change control Neuromuscular, balance disorders, lack of strength and decreased postural control. ${ }^{6}$

Functonal Ankle Instability (FAI) refers to the subjective feeling of the ankle "feeling wobbly" that remains as a result of an ankle sprain. ${ }^{7,8}$ Causes of FAI include muscle weakness and a lack of proprioceptive feeling. Functional Ankle Instability results in disruption of functional activities in someone who is active in sports activities, especially those who are actively involved in sports activities. Disruption of functional activities will cause repeated injuries which will certainly hinder the performance of an athlete. ${ }^{8}$
Functional ankle instability is defined as the subjective feeling of ketida kstabilan and repetitive injury to the ankle, ankle sprain symptomatic (or both) for proprioceptive and neuromuscular deficits. ${ }^{9}$

Functional Ankle Isntability describes the perception of the ankle feeling shaky, feeling weaker, more sore or painful, or experiencing functional limitations after an ankle injury. ${ }^{10}$

Pathology Functional ankle instability occurs in muscle and neuromuscular control of the lower limb. When experiencing an injury, a person will automatically take care of the injured part of the body by resting the injured part and maximizing movement and support on the part of the body that is not injured, this is done to avoid pain or soreness when doing activities or movements. From the effect of immobilization on the injured part of the body in addition to damage to the muscle ligaments, strength is also decreased, and this will be followed by disruption of postural control or proprioceptive disorders of the injured body. ${ }^{11}$

Decreased muscle strength and the appearance of propriseptive disturbances will result in muscle imbalance or imbalance of muscle work, either on the same leg or on the opposite leg. In atlet experiencing Functional Ankle instability then becomes bad postural control and cause balance disorders. ${ }^{12}$

Strength or strength, which is the ability of the human physical condition that is needed to increase learning achievement. Strength is an element of physical condition that is very important in sports because it can help improve components such as speed, agility and accuracy. ${ }^{13}$

While strength training is a stimulus exercise that is very important to encourage changes in muscle strength, muscle size and muscle power. ${ }^{14}$ For impaired stability Functional ankle strengthening exercises are aimed at strengthening the ankle muscles which involve inversion, eversion, plantar flexi and dorsal flexi movements. 
Proprioceptive is defined as a sensory modality that includes sensation of joint motion, or quinesthesia, and a sense of joint position. Proprioceptive is the most important part in maintaining balance. Proprioceptive is the perception of body position and movement in three-dimensional space, the overall proprioceptive performance is determined by the quality of proprioceptive information and individual proprioceptive abilities available. In its journey, peripheral mechanoreceptors that arise from the limbs provide proprioceptive information to the brain (central processing ) to be integrated and used. ${ }^{15}$

Propriose ptif as a measure of the neuromuscular response to stimuli received by the body must involve sensory input, central processing, and motor output. ${ }^{15,16}$ Proprioception plays an important role in the control of human movement, which is fundamental to daily activities, sports, and exercise. ${ }^{15}$

Proprioceptive exercises will inform movement precision and muscular reflexes that contribute to the formation of dynamic stability of the joints. The goal of proprioceptive training is to retrain the afferent pathways to develop sensation of joint motion and motor activation of the central nervous system. Proprioceptive exercise is very important to do because proprioceptive feedback will increase and maintain joint functional stability.

The purpose of this study was to develop rehabilitation therapy methods using strengthening exercise and proprioceptive exercise methods to improve ankle functional stability in cases of functional ankle instability.

\section{MATERIALS AND METHODS}

\subsection{Participants}

The sample in this study was 20 athletes with Functional Ankle Instability disorders with a Cumberland Ankle Instability Tool examination value of not more than 24 . The study sample was male aged 18 to 28 years.

\subsection{Methods}

This study used the Research and Development research method by developing physical rehabilitation therapy for Functional Ankle Instability with the Strenghthening exercise and Proprioceptive Exercise methods. The stages of the research carried out can be seen in the chart below.

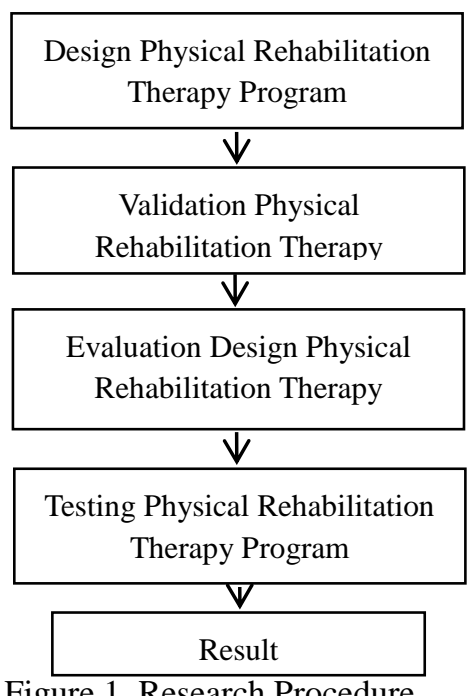

Figure 1. Research Procedure

Validation of designs made involving sports experts and training programs. The design validation was in the form of a questionnaire with 10 questions relating to the strengthening exercise design and proprioceptive exercise. The resulting design for a strengthening exercise is 2 types of exercise, namely isometric exercise and dynamic exercise using Resistance Band Yoga media and involves 4 movements in the ankle, namely inversion, eversion, plantar flexi and dorsal flexi. Proprioceptive exercise is carried out with 2 training models, namely isometric exercise and dynamic exercise using bosu ball media. Isometric exercises include single leg stand and double leg stand on the bosu ball. And dynamic exercises include 4 single leg stand movements, double leg stands, squats and combination exercises for zigzag running, standing and suad on a bosu ball. The trial of the resulting therapy design using experimental methods on 20 samples, the study was carried out for 6 weeks 3 times a week. 


\section{RESULT}

\subsection{Therapeutic Model Design Validation}

Of the 10 Quesionare questions submitted to the 3 experts involved in the study, it was found that the average value obtained was 4.1 with the category of the validation result of the therapeutic model was $82 \%$ and it was considered good enough to be used as an exercise in functional ankle stability.

\subsection{Effect of Exercise Methods on increasing ankle functional stability}

The resulting trial therapy program was given to 20 male athletes from various sports who experienced functional ankle instability disorders with a Cumberland ankle instability tool (CAIT) value of not more than 24. Overall the characteristics of the study sample can be seen in the following table:

Table 1. Research characteristics

\begin{tabular}{|l|c|c|}
\hline & Mean \pm SD & Range \\
\hline Age $(\mathrm{yr})$ & $26.30 \pm 2,349$ & $20-28$ \\
\hline Height $(\mathrm{cm})$ & $168.10 \pm 4,025$ & $160-175$ \\
\hline Weight $(\mathrm{kg})$ & $66.64 \pm 4,945$ & $58-75$ \\
\hline CAIT Pre Test & $20.70 \pm 1.478$ & $18-23$ \\
\hline CAIT Post Test & $25.65 \pm 1.137$ & $24-28$ \\
\hline
\end{tabular}

The results of the normality test in the study used the Shapiro-Wilk test with the following results:

Table 2 Test of Normality

\begin{tabular}{|l|l|c|}
\hline & $\mathrm{N}$ & $\mathrm{P}$ \\
\hline CAIT Score Pretest & 20 & 0.237 \\
\hline CAIT Score Posttest & 20 & 0.083 \\
\hline
\end{tabular}

From the results of the normality test of the research data, it was obtained a $\mathrm{P}$ value $>0.05$, which means that the research data in this study were normally distributed and the next test stage could be carried out by using the t test to measure the difference before and after the exercise method treatment.

The results of the research which was conducted for 6 weeks 3 times a week to the research sample obtained the following results:

Table 3. Paired Sample T-Test Product Trials

\begin{tabular}{|l|c|c|c|}
\hline \multirow{2}{*}{$\mathrm{N}=20$} & Pretest & Posttest & \multirow{2}{*}{$\mathrm{P}$} \\
\cline { 2 - 3 } & Mean $\pm \mathrm{SD}$ & Mean $\pm \mathrm{SD}$ & \\
\hline $\begin{array}{l}\text { CAIT } \\
\text { Score }\end{array}$ & $20.70 \pm 1.478$ & $25.65 \pm 1.137$ & 0.000 \\
\hline
\end{tabular}

The T test in this study used Paired sample T-Test to see the difference in the CAIT value before the therapy treatment and after the therapeutic method was done. The results showed that the provision of Strengthening Exercise and Proprioceptive Exercise on functional ankle instability had a significant effect on improving the value of ankle functional stability with a pre-test mean of $20.70 \pm 1.418$ and a post-test mean of $25.65 \pm 1.137$ with a value of $\mathrm{p}=0.000(\mathrm{p}<0.05)$

\section{CONCLUSION}

The combination of Strengthening Exercise and Proprioceptive Exercise can improve the functional stability of the ankle in cases of functional ankle instability. This can be seen from the results of the study where $\mathrm{P}=0.000(\mathrm{p}<0.05)$, this indicates a significant difference between the pre-test and post-test functional ankle instability with the provision of the two therapeutic methods produced in the study.

In this study, the measurement of the stability value only uses the Camberland Ankle Instability Tool (CAIT). This research instrument was used as an evaluation of the proprioceptive exercise program and the strengthening exercise to improve ankle functional stability. The evaluation of the results of the study was not based on individual training methods, namely proprioseptive and strengthening, but the evaluation was based on the impact of the two training methods on improving ankle functional stability. 
The use of resistance bands with isometric and dynamic exercise working principles is aimed at increasing the strength of the muscles in the ankles with these two principles, the resulting impact is the emergence of strength from the ankle muscles as a basis for motion (base off support) for individuals.

The use of the Bosu ball is specifically aimed at improving proprioceptive work by utilizing unstable footing on the ball. This will trigger the neuromuscular work in controlling the movements caused by doing isometric and dynamic exercises.

Results in line with research conducted by Ki Jong Kim, et al with the title Research Which is More Effective Treatment for Functional Ankle instability: Strengthening or Combined Muscle strengthening and Proprioceptive Exercises?. This study aims to apply a combination of strength training and prorioceptive training and to test the effectiveness of a combination of the two training methods on impaired ankle functional stability. ${ }^{8}$

In this study, the research sample consisted of 30 people who were divided into three groups, one control group and one muscle strengthening group and one group combined strength and proprioceptive training. The instrument used to measure the functional stability of the ankle in this study was the Cumberland Ankle Instability Tools, while the research sample selected in this study was 30 healthy adults, women and men who had a history of ankle sprains and felt a sense of ankle instability, with a Cumberland score ankle instability tool not more than 24 points. The instrument for measuring the strength of the ankle muscles uses a Biodex III isokinetic dynamometer (Biodex medical system). The results obtained in this study were a significant difference in the increase in the strength of the inversion, eversion, plantar and dorsal flexi muscles in the treatment group when compared to the control group. $^{8}$

For the Cumberland ankle instability tool, the combination of strength training and proprioceptive training showed a significant difference compared to the other two groups. From this research, it can be concluded that a combination of strengthening exercise and proprioceptive exercise is more effective in increasing functional ankle instability.

Providing a combination of proprioceptive and strenghthening exercises to functional ankle instability is very beneficial for increasing ankle stability.

The strengthening of ankle stability allows the athlete to avoid repeated injuries to the ankle.

\section{ACKNOWLEDGMENTS}

The application of a combination of proprioceptive and strengthening exercise methods in cases of functional ankle instability needs to be improved, especially in the application of a wider research sample and to keep abreast of any existing theoretical developments, especially with regard to cases of functional ankle instability that develop from cases of chronic sprained ankle.

\section{REFERENCES}

[1] Sumartiningsih, S. 2012. Injuries to the ankles (Ankle Sprains). Journal of Indonesian Sport Science edia Vol 2. Edition 1. July 2012. ISSN: 2088-680

[2] Hertel, J. 2008. Sensorimotor Deficits with Ankle Sprains and Chronic Ankle Instability, Clinics in Sport Medicine. Virginia. Elsevier.

[3] Lambers, K., Ootes, D., \& Ring, D. 2012 Incidence of Patients with Lower Extremity Injuries Presenting to US Emergency Departments by Anatomic Region, Disease Category, and Age. Clinical Orthopaedics and Related Research $\AA$, 470(1), 284-290 doi:10.1007/s11999-011-1982-z

[4] Page, P., Baton R., Clare C.F. 2010. Assessment and Treatment of Muscle Imbalance The Janda Approach. Los Angeles, CA. Human Kinetics.

[5] Lauren, C.O., Christopher, R..C., et.al,. 2002. Efficacy of the Star Excursion Balance Tests in Detecting Reach Deficits in Subjects With Chronic Ankle Instability, Pennsylvania State University, University Park, PA

[6] Hertel, J. 2002. Functional Anatomy, Pathomechanics, and Pathophysiology of Lateral Ankle Instability, Pennsylvania State University, University Park, PA

[7] Ji. SW, Kim HS, Kwon KW, et al. 2004. : The ankle strength, balance and functional ability of the adolescent volleyball players with functional ankle 
instability. Korean J Phys Educ, 43: 567-577.

[8] Kim, KJ, Kim YE, et.al. 2014. Which Treatment is More Effective for Functional Ankle Instability: Strengthening or Combined Muscle strengthening and Proprioceptive Exercises?.J. Phys. Ther. Sci. 26: 385-388.

[9] Tropp, H. 2002. Comentary : Functional Ankle Instability Revisited. Journal of Athletic Training ;37(4):512-515

[10] Munn, J., Sulivan, SJ., Schneider, AG. 2010. Evidence of sensorimotor efificits in functional ankle instability: A systematic review with meta-analysis. Elsevier Ltd. All rights reserved. doi:10.1016/j.jsams.2009.03.004

[11] Syafrianto, D., Mangku Karmaya, N., Lesmana, S., Ngurah, I., Weta, I., \& Imron, M. (2017). Addition of Glute Exercise to Basic Exercise Therapy Increases Ankle Stability in Chronic Ankle Sprain Patients. Sport And Fitness Journal. Retrieved from

https://ojs.unud.ac.id/index.php/sport/article/view/ $\underline{31853}$

[12] Dale, B. 2006. Functional Rehabilitation After Lateral Ankle Injury. 2006 Human Kinetics · ATT 11(3), pp. 52-55

[13] Chan, F. (2013). Strength Training (Latihan Kekuatan). Cerdas Sifa Pendidikan,

[14] Jovanovic, Mladen and Flanaga, EP. 2014. Researched Applications Of Velocity Based Strength Training. J. Aust. Strength Cond. 22(2)58-69.

[15] Han, Jia., Waddington, W. et.al. 2016. Assessing proprioception: A critical review of methods. Elsevier B.V. on behalf of Shanghai University of Sport, 2095-2546, doi.org/10.1016/j.jshs.2014.10.004

[16] Ashton-Miller JA, Wojtys EM, Huston LJ, Fry-Welch D. Can proprioception really be improved by exercises? Knee Surg Sports Traumatol Arthrosc 2001;9:128-36. 